\title{
Estimation of kinetic parameters for the transport of nitrate and ammonium into marine phytoplankton
}

\author{
Kevin J. Flynn* \\ Swansea Algal and Plankton Research Unit, University of Wales Swansea, Singleton Park, Swansea SA2 8PP, Wales, UK
}

\begin{abstract}
Methods for the determination of kinetic parameters for the transport of ammonium and nitrate into phytoplankton are considered using simulations generated by the ammonium-nitrate interaction model (ANIM; Flynn et al. 1997, Phil Trans R Soc Lond B 352:1625-1645). Problems associated with experimental conditions such as incubation periods, non-constant substrate concentrations (including variations in the isotope ratio in ${ }^{15} \mathrm{~N}$ assays), presence of the counter nutrient, and different cellular $\mathrm{N}$ status are considered. Depending on the period of incubation and the biomass, errors occur which can result in an over or underestimate of the half saturation constant for transport $\left(K_{t}\right)$, while the maximum transport rate $\left(V_{1_{\text {mur }}}\right)$ is underestimated unless derepression of nutrient transport and/or dssinulation uccurs. Because of the effects of intraceiluiar feedback processes on transport, there may be little advantage in conducting studies using stable substrate concentrations rather than determining transport rates from the decrease in substrate concentrations. Differentiating quadratic curve fits through plots of cumulative transport against time provides a simple method for estimating the initial (zero time) transport rate. Simulations within a simple photic zone model run using different kinetic parameters for algal nutrient transport indicate that post-transport processes are, within reasonable bounds, likely to be at least as important as $V_{\mathrm{t} \text { ma }} / K_{\mathrm{t}}$ for success of the algae. Estimates of transport kinetics for different species, and other factors such as cell size and shape which may affect transport, should not be used alone to infer a competitive advantage or disadvantage for the individual species. These results have similar implications for studies of nutrient transport into other microbes such as bacteria and mixotrophic protists.
\end{abstract}

KEY WORDS: Ammonium - Nitrate $\cdot$ Transport $\cdot$ Uptake kinetics $\cdot$ Simulation

\section{INTRODUCTION}

Nitrate and ammonium between them are the major $N$ sources for the support of phytoplankton growth. Further, the ratio of their utilization [the f-ratio, simplified in this case to $V_{\text {nitrate }} /\left(V_{\text {nitrate }}+V_{\text {ammonium }}\right) ;$ Dugdale \& Goering (1967)] may be taken to indicate the proportion of production supported by 'new' nitrogen (nitrate regenerated in deep waters rather than that supported by $\mathrm{N}$ cycling in the photic zone (ammonium). Fundamental to our understanding of the relative importance of nitrate and ammonium usage is a knowledge of the transport rates into the algae.

\footnotetext{
•E-mail:k.j.flynn@swansea.ac.uk
}

The subject of nutrient transport has been reviewed by McCarthy (1981), Syrett (1981) and Wheeler (1983), with more specialised works by Raven (1980; transport mechanisms), Morel (1987; aspects of the relationship between assimilation and transport kinetics for nutrients in general), Harrison et al. (1989; experimental methods for the determination of uptake kinetics), Aksnes \& Egge (1991; biological and physico-chemical aspects of substrate-porter interactions), and Berges et al. (1994; use of different mathematical fits of rectangular hyperbolae). However, an integrated review of the implications of these processes for studies of transport kinetics is lacking. Although this current work refers primarily to ammonium and nitrate transport, the conclusions have wider applicability both for nutrient transport in other microbes (such as bacteria and 
fungi) and also for the estimation of kinetic parameters describing predation by plankton, which may also be subject to various feedback processes

Throughout this work, the term 'transport' is used to describe the passage of the nutrient across the plasma membrane into the cell and 'assimilation' to describe the entire process from transport through to full incorporation. It is very difficult, if not generally logistically impossible, to study transport itself because of the effects of post-transport feedback processes which may commence within minutes, or even seconds, after a nutrient is again made available to nutrient-stressed cells. What is usually measured, 'uptake', thus includes various other regulated processes such as accumulation into internal inorganic nutrient pools as well as reduction (for nitrate) and incorporation into amino acids and other organics. The implications of this problem are well known (Glibert \& Goldman 1981, Goldman \& Glibert 1982, Collos 1983), often giving the symptom of 'surge uptake' followed by a period of declined transport rates.

The determination of the kinetic parameters of transport and assimilation into cells for different nutrients is thus a complex subject affected primarily by the time scale of interest. Transport kinetics are, at first sight, only of importance over the second to minute scale, while assimilation kinetics operate over significant periods of the growth cycle. However, what happens at the point of transport affects all subsequent events and it is thus potentially of importance for assimilatory kinetics in total. The terms $V_{\mathrm{t}_{\max }} K_{t}$ and $V_{\mathrm{a}_{\max }} K_{\alpha}$ are used here to define respectively the maximum velocity and half saturation substrate concentrations for transport and assimilation [through to whole cell growth, not just to amino acids as described by Harrison et al.'s (1989) $K_{1} J$. Thus, by analogy with the MichaelisMenten equation,

$$
V_{\mathrm{t}}=V_{t_{\max }} \cdot \frac{[\mathrm{S}]}{[\mathrm{S}]+K_{\mathrm{t}}}
$$

where $[\mathrm{S}]$ is the substrate concentration and $V_{1}$ the resultant rate of transport.
There are several major types of potential error associated with studies of inorganic- $\mathrm{N}$ transport kinetics, as given in Table 1. The consequences of these errors will be illustrated in this paper. It should be noted that these errors are not peculiar to phytoplankton, but will also affect studies of bacteria and other microbes, and that (especially in field situations) there may be additional important sources of error. Because N-stressed cells may show much higher initial rates of transport when a nutrient suddenly becomes available (e.g. Syrett et al. 1986), the period of time before error Type I becomes significant is likely to decline with increasing $N$ stress and to be relatively worse for ammonium which enters the cell more rapidly than nitrate and thus comes under feedback regulation quickly. Many workers have used the rate of decrease in substrate concentration, [S], to determine transport (e.g. see those referenced by Harrison et al. 1989). This may give rise to a Typc II crror, where there is a significant decrease in [S] during the incubation which is not properly accounted for in the calculations. This is most likely to occur together with the Type I error because it is in part a function of incubation period.

Ideally incubations would be conducted in the presence of a single substrate but in reality this is not always so (especially for natural samples). As a consequence there is the problem of interactions between the assimilations of different nutrients, in this case ammonium and nitrate. This particular interaction is complex (Dortch 1990, Flynn 1991, Flynn et al. 1997), but essentially results in a 'preference' for ammonium (although the converse may occur at low ammonium concentrations; Dortch 1990, Flynn et al. 1997). Nitrate and ammonium do not share the same porter, and the interaction is primarily due to products of the subsequent $N$ assimilation. This Type III error, associated with the interaction of ammonium and nitrate transports, will also be exacerbated by the incubation period (Type I error). Again analogies will exist in other systems, for example between the interactions of amino acid and ammonium transports in bacteria (e.g. Middelboe et al. 1995).

Table 1. Types of error induced by experimental protocol during attempts to determine the maximum rate of transport $\left(V_{t_{m a s}}\right)$ and half saturation constant $\left(K_{\mathrm{t}}\right)$

\begin{tabular}{|llll|}
\hline Type & Cause & Comment or explanation & $\begin{array}{c}\text { Likely associated } \\
\text { errors }\end{array}$ \\
\hline I & Prolonged incubation period & Initial transport kinetics overridden by assimilation kinetics & I \\
II & Substrate concentration falls & External conditions not constant & I, II \\
III & Ammonium-nitrate interaction & Repression of transport by transport of the counter nutrient & I, II, III \\
IV & $\begin{array}{l}\text { Changes in isotopic composition } \\
\text { in mixed populations }\end{array}$ & Significant $\mathrm{N}$ cycling during ${ }^{15} \mathrm{~N}$ incubations in the field & \\
\end{tabular}


In addition, for attempts to determine kinetic parameters in field populations there is a potential error associated with the use of ${ }^{15} \mathrm{~N}$ if isotope dilution occurs due to nutrient regeneration. The Type IV error will invariably also occur with the other types because of the period of incubation (possibly of many hours duration in oceanic or offshore waters, e.g. Harrison et al. 1996), and the presence of the counter mutrient(s). There are additional potential problems with field experiments, such as those associated with bacteriaalgal competition for ammonium (Kirchman 1994) and the release of dissolved organic N (DON) (Bronk et al. 1994), but these are not considered in detail here.

The aims of this paper are 2 -fold. Firstly to examine the implications of the experiment design for estimation of kinetic parameters, considering the sources of error given in Table 1 . This is performed using a complex dynamic mathematical model of the interactions between ammonium and nitrate-the Ammonium, Nitrate Interaction Model (ANIM) of Flynn et al. (1997). The use of this model, which can reproduce the major documented interactions between algal transport and growth using these nutrients, enables a consideration of kinetics which would be difficult or effectively impossible using experimental methods. Secondly, the consequences for the operation of ecosystem simulations of using inaccurate estimates of kinetic parameters describing phytoplankton nutrient transport will be considered.

\section{METHODS}

Model. The ANIM as described by Flynn et al. (1997) has been used for most of this work. ANIM describes a generic cell type with, for each nutrient, a fixed substrate transport affinity $\left(K_{t}\right)$ but a variable maximum transport rate $\left(V_{t_{\max }}\right)$ depending on the $\mathrm{N}$ status of the cell. While there is no good evidence that $K_{1}$ varies with nutrient history, the variable nature of $V_{t_{\max }}$ is well known (e.g. Collos 1980, Dortch et al. 1982). Changes in $V_{\mathrm{I}_{\text {max }}}$ have been related to the relative growth rate or to the cellular N:C ratio (the N quota, or $Q$ ) via the cell quota kinetics of Caperon (1968) and Droop (1968) by Goldman \& Glibert (1982) and Morel (1987). However, the control of transport is far more rapid than a simple association with $Q$ would suggest. In ANIM the absolute maximum transport rate at any point in time is a function of $Q$, but there are feedback mechanisms limiting transport both from the size of the internal inorganic nutrient pools and from the size of the glutamine (Gln) pool. In the model as described by Flynn et al. (1997), cells using ammonium can attain a higher $N: C$ and growth rate than those using nitrate. At steady state the maximum theoretical rates of $\mathrm{N}$ assim- ilation $\left(V_{a_{\max }}\right)$ and the substrate concentrations required to support half $V_{a_{\max }}\left(K_{\mathrm{c}}\right)$ are, respectively, $7 \mu \mathrm{g} \mathrm{N} \mathrm{mg}^{-1} \mathrm{C} \mathrm{h}^{-1}$ and $0.193 \mu \mathrm{M}$ for ammonium, and $6 \mu \mathrm{g} \mathrm{N} \mathrm{mg}{ }^{-1} \mathrm{Ch}^{-1}$ and $0.209 \mu \mathrm{M}$ for nitrate.

Data handling. Experimental protocols for measuring 'uptake' kinetics typically involve the addition of substrate at different concentrations into aliquots of the cell suspension, and then sampling at suitable time points of the medium and/or the cells to measure the disappearance or appearance (respectively) of the nutrient. In most instances, the simulated incubations were run for up to $3 \mathrm{~h}$ (the time used with oceanic samples by Harrison et al. 1996), with data archived with a resolution of around $1 \mathrm{~min}$. Initial substrate concentrations were $0.25,0.5,1,2,4$ and $8 \mu \mathrm{M}\left(K_{l}=1 \mu \mathrm{M}\right)$, except for the simulations of an ocean photic zone which used $0.0625,0.125,0.25,0.5,1,2$ and $4 \mu \mathrm{M}$ (values of $K_{\mathrm{t}}$ being lower at $0.2 \mu \mathrm{M}$ ). Selected data points, representing sampling times for experimental work, have been chosen for subsequent analysis. The shortest chosen period, 6 min, equates with the likely minimum period of incubation one would use with standard ${ }^{15} \mathrm{~N}$ methods (given the time taken to sample, filter, wash with ${ }^{15} \mathrm{~N}$-free medium, remove and replace the filter, while running simultaneous incubations at a minimum of 5 substrate concentrations staggered by $1 \mathrm{~min})$.

For each of the sampling times the average transport rate was computed by division of the cumulative transport into the cell by the elapsed time $\left(V^{t_{0}-t_{0}}\right)$. This method contrasts with that used by Goldman \& Glibert (1982) and Harrison et al. (1989), who, using the notation $V^{t_{1}-t_{2}}$, indicated the average rate of transport between times $t_{1}$ and $t_{2}$. Values of $V^{t_{1}-t_{2}}$ provide estimates of the instantaneous rates of transport which the model can provide (and were recorded) as precise values at a given time t. Fig. 1 shows a simulated experiment with the transport rates of ammonium and nitrate varying with time on addition of a pulse of nitrate together with a 'contaminating' source of ammonium. A comparison between average and instantaneous transport rates is given in Fig. $1 \mathrm{~b}$. The changes in these rates reflect the interactions of transport and posttransport processes; in the model short-term regulation operates via the internal nutrient pools and the concentration of Gln, the first organic product of ammonium assimilation. For nitrate, for example, there is a filling of the internal nitrate pool and a decline in transport rates (around 0.25 to $0.75 \mathrm{~h}$ ) with the accumulation of Gln during ammonium assimilation. Around $1 \mathrm{~h}$, when the supply of ammonium became limiting and internal Gln declined, nitrate assimilation rates increased. Some of the plots presented show how the value of the estimate of the kinetic parameters changes depending on the (end) time of the incubation (i.e. 

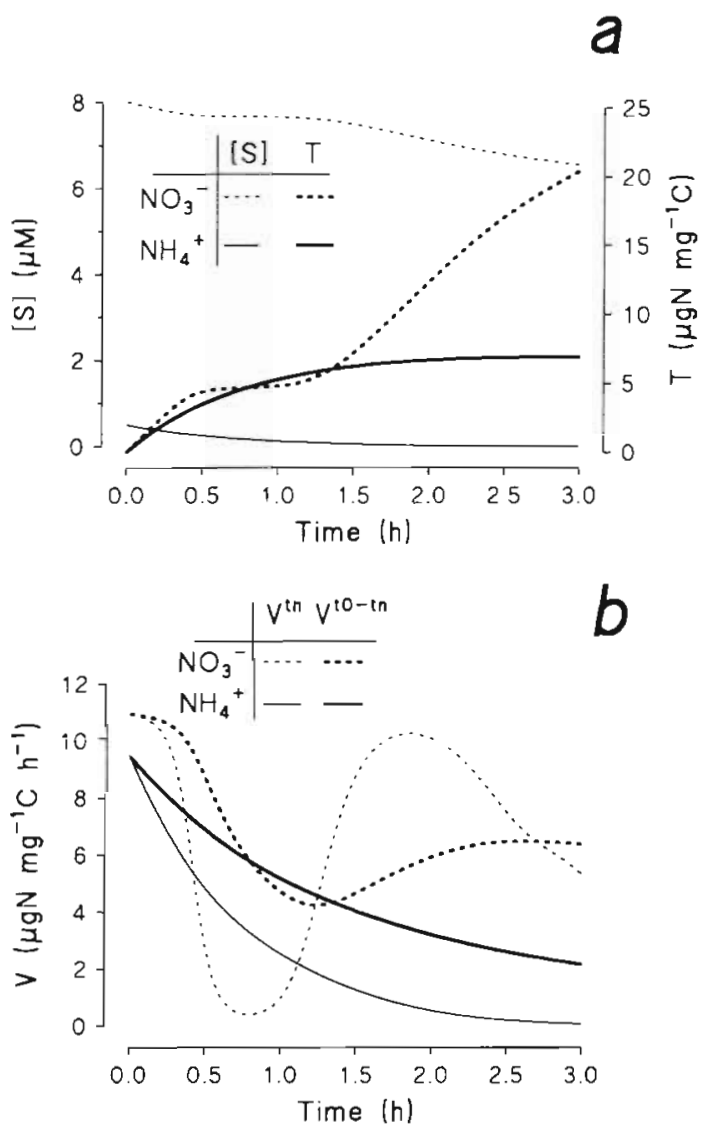

Fig. 1. An example of model output for the simultaneous transport of nitrate and ammonium, showing (a) decline in substrate [S], and changes in cumulative transport $T$, and (b) comparison between instantaneous, $V^{t h}$, and average, $V^{t_{0}-t_{n}}$, transport rates with time

$\left.V^{t_{0}-t_{n}}\right)$. In these plots, the figure at zero time $\left(t_{0}\right)$ is the real value.

The optimal method of determining transport kinetics would be to determine rates at $t_{0}$, before any internal feedback mechanisms came into play and before any decrease of [S]. [The only problem here being at very low concentrations with the interaction between initial absorption and transport as transport per se commences (Raimbault \& Gentilhomme 1990).] In recognition of this, Harrison et al. (1989) recommend the use of $V^{t_{1}-t_{2}}$ where $t_{1}=0$ and $t_{2}=2 \mathrm{~min}$. This value is thus the same as $V^{t_{0}-t_{n}}$, where $t_{\mathrm{n}}=2 \mathrm{~min}$. The shape of the curves generated from plotting cumulative transport against sample time are variable in shape and, while ideally they should be linear, are often curvi-linear or perhaps more complex (e.g. Fig. 1a). Because of the nature of the interactions, leading to a decline in transport rates over the course of the incubation (according to the type of error; Table 1), there is no justification for using any particular curve-fit through measured values of cumulative transport $(T)$ versus time in order to estimate $V^{t_{0}}$. Thus, as the simplest approximation, the initial transport rates were also estimated by plotting a quadratic equation through values of $T$ and forced through the origin. Differentiating the equation $T=a t^{2}+b t$ with respect to time and setting $t=0$ gives $V^{t_{1}}=b$ (where $T$ is cumulative transport, $t$ is time, $a$ and $b$ are constants, and $V^{h}$ is the initial rate of transport). While such a curve could be fitted through just 2 data points (and the origin), in reality the experimenter will probably wish to use more because of the likely errors associated with each (especially the first) data point; 3 thus seems the likely minimum number of points one would use to estimate $V$ at each value of [S] (typically 6,12 and $18 \mathrm{~min}$ in this case).

Berges et al. (1994) report the implications of using various mathematical methods for the determination of kinetic parameters, recommending the use of iterative methods (as supplied by Jandell's SigmaPlot and BioSoft's Fig.P) which have been used here.

\section{TEST SCENARIOS AND RESULTS}

Temporal responses shown here are those of ANIM as described by Flynn et al. (1997). It must be stressed that the time scale of the events will be decreased significantly by the use of a higher biomass, with organisms with higher intrinsic transport and/or growth rates, and with internal nutrient pools of different size. The form and magnitude of the relationship between $V_{t_{m a x}}$ and $Q$ is of particular importance for the simulation of 'surge uptake'. For nitrate the level of nitrate/nitrite reductase is also important. However, the conclusions drawn from the simulations shown here remain the same.

\section{Incubations where substrate levels remain stable}

Ideally, kinetic parameters should always be determined by estimation of rates over a range of fixed substrate concentrations [S]. This would require the determination of the rate of appearance of the substrate within the cells which are in such a dilute suspension that a non-significant decline in [S] occurs during the incubation. Such experiments would involve using ${ }^{15} \mathrm{~N}$, or perhaps ${ }^{13} \mathrm{~N}$ substrates (Zehr et al, 1988), or for robust cell types the cell-on-filter method of Parslow et al. (1985). To examine this approach ANIM was configured to start with cells which had been grown in steady state on ammonium-nitrate and hence have an operational, derepressed, nitrate assimilation pathway. This was done at dilution (growth) rates of $0.02 \mathrm{~h}^{-1}(\mathrm{Q}=$ 0.0764 , growth rate of $40 \%$ of theoretical maximum) or 
Fig. 2. Changes in estimated $K_{\mathrm{t}}$ and $V_{\mathrm{tmax}}$ values for ammonium and nitrate in simulated cells previously grown on ammoniumnutrate at $40 \%(Q=0.0764$, circles) or $70 \%(Q=0.142$, triangles) of maximum theoretical growth rates. Incubations were made under conditions in which substrate concentrations did not alter during the $3 \mathrm{~h}$ period (fixed $[\mathrm{S}]$ ), in the presence iclosed symbols and dashed lines) or absence (open symbols, solid lines) of the counter nutrient $10.5 \mu \mathrm{M}$ ammonium for the nitrate kinetics, and $4 \mu \mathrm{M}$ nitrate for ammonium kinetics). Real values of $K_{1}$ and $V_{I_{\max }}$ are the figures at time $0 \cap n$ the graphs
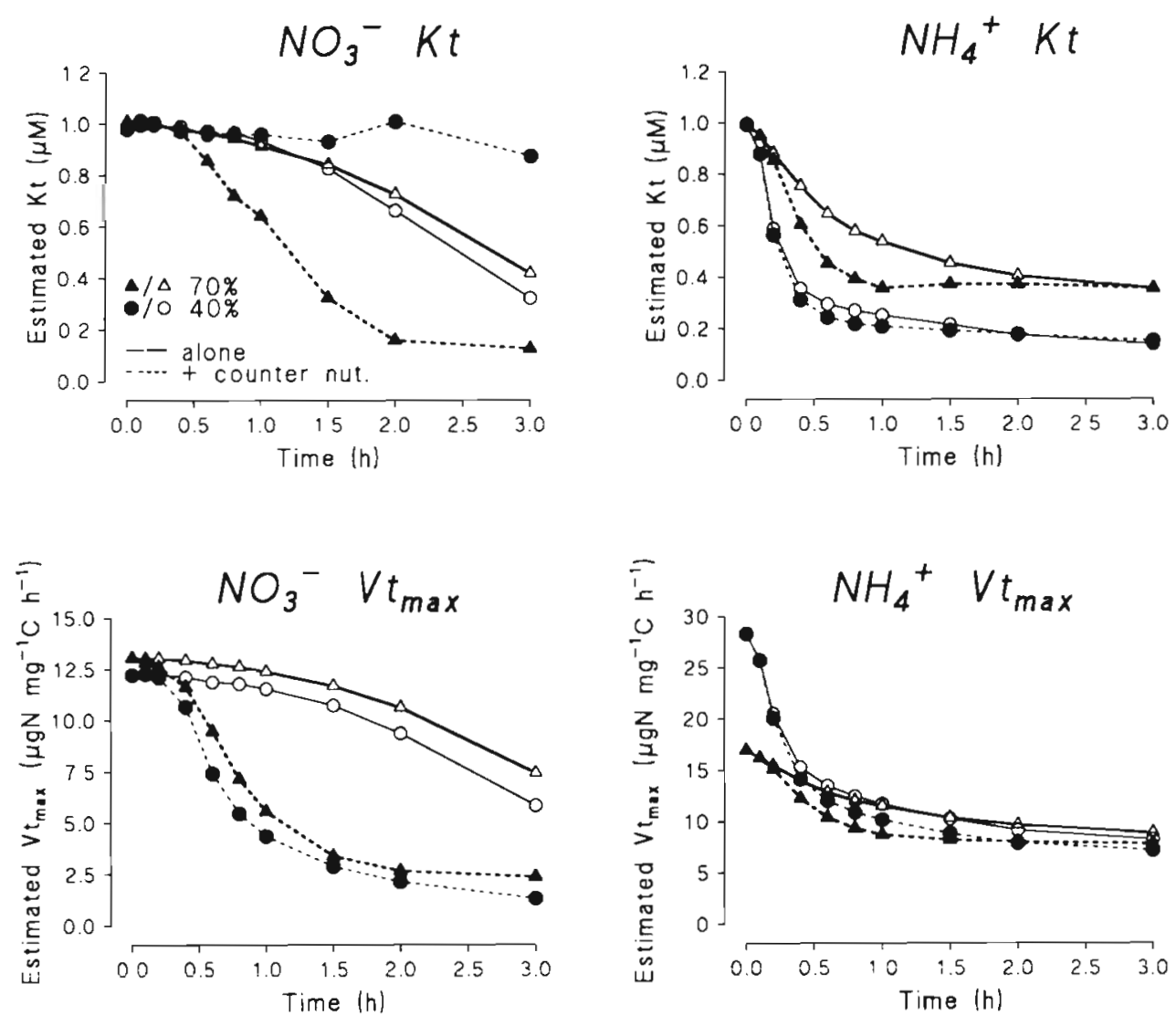

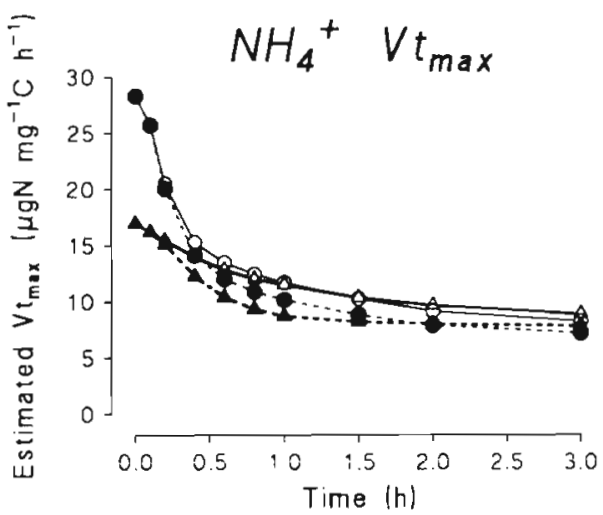

$0.035 \mathrm{~h}^{-1}(\mathrm{Q}=0.142$, growth rate of $70 \%$ maximum). The maximum theoretical carbon-specific growth rate was set at $0.05 \mathrm{~h}^{-1}$, equivalent to $1.2 \mathrm{~d}^{-1}$ in continuous light. Simulated incubations were conducted either in the presence of a zero concentration of the counter substrate or with $0.5 \mu \mathrm{M}$ ammonium or $4 \mu \mathrm{M}$ nitrate for the nitrate and ammonium series respectively; these are values shown by Flynn et al (1997) to affect steady-state transport of the counter nutrient using this model configuration. Incubations assumed continuous illumination and the value of [S] for both test and (where applicable) counter nutrient remained fixed. The real value of $K_{1}$ was set at $1 \mu \mathrm{M}$ for both substrates, while $V_{1_{\max }}$ varied as a function of the $N$ status $(Q)$ as described by Flynn et al. (1997). Between them these simulations illustrate the implications of errors of Types I and III (Table 1).

In the absence of a counter substrate, the general trend is that when [S] remains constant during the incubation (Fig. 2) the estimates of $K_{\mathrm{t}}$ and $V_{\mathrm{t}_{\max }}$ fall with incubation time. This is due to the development of feedback regulation as the internal nutrient pools fill (not shown) and occurs quickest with the higher concentrations of [S] and when transport is most rapid (e.g. ammonium transport into cells of lower $\mathrm{N}$ status). The presence of the counter nutrient generally exacerbates the decrease in these estimates because the additional $\mathrm{N}$ flowing through the cell results in a more rapid development of the feedback mechanisms affecting transport of both nutrients.

\section{Incubations where substrate levels decline}

In experimental studies [S] may often decline significantly during the incubation. Incubations at the lower values of [S] will show the greatest proportionate decrease in [S] and, because these fall in the initial near-linear section of the hyperbolic curve, these will also have most effect on transport rates. To test the consequences of a decrease in [S] during the incubation, ANIM was configured as for fixed [S] (see above)

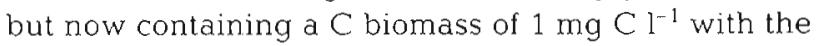
value of $[S]$ decreasing in response to transport into that biomass. This illustrates the implications of errors of Types I, II and III (Table 1).

The situation when [S] is not fixed (Fig. 3) is more complex than when it is fixed (Fig. 2). Initially estimates of $K_{\mathrm{t}}$ may fall due to feedback events but then, because the transport at the lower [S] decreases disproportionately as the nutrient is consumed (Fig. 3), the values of $K_{t}$ may then rise. Generally estimates of 

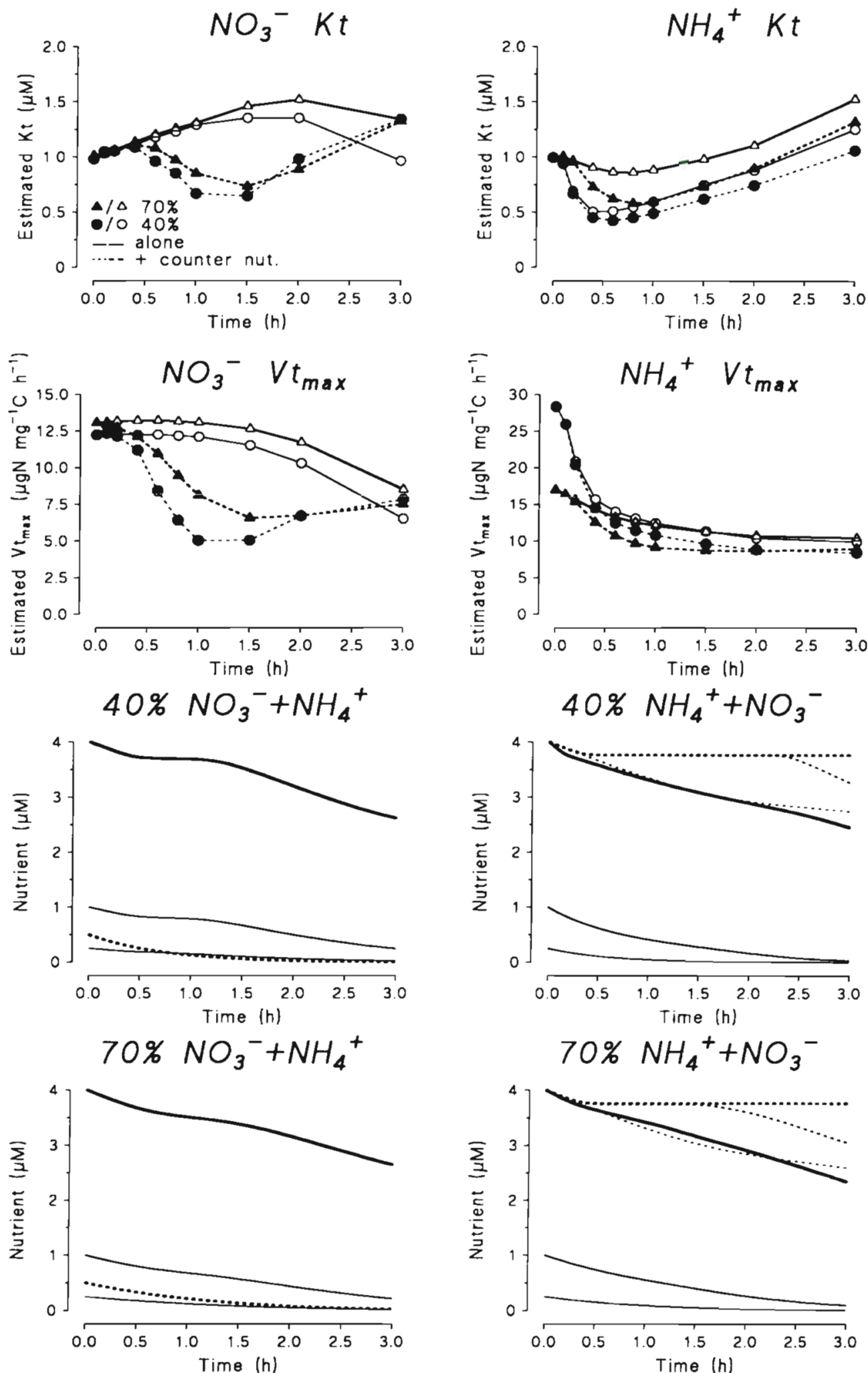

Fig. 3. As Fig. 2, but where [S] decreased during the incubation in response to transport into a biomass of $1 \mathrm{mg} \mathrm{Cl}^{-1} \mathrm{Plots}$ are also given of changes in nutrient concentrations for the incubations including the counter nutrient; only 3 concentrations of the test [S] are shown of the 6 used. Concentrations of the counter nutrient are indicated with dashed lines of the same thickness as the appropriate solid line for the test nutrient (these overlap for ammonium in the nitrate series) 


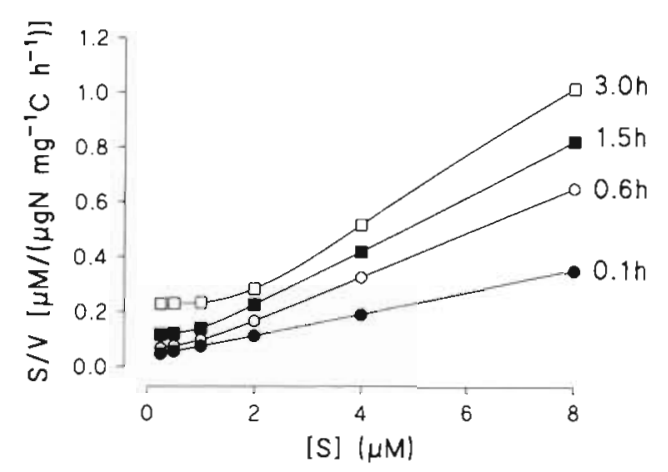

Fig. 4. Linear transforms of data for the $40 \% \mathrm{NH}_{4}{ }^{+}$-alone (without counter nutrient) incubations shown in Fig. 3. The data points are average transport rates $V^{t_{0}-t_{n}}$ taken at times $t_{n}$ between 0.1 and $3 \mathrm{~h}$. Note that, although the rates are plotted against constant values of $[S \mid$ las may be assumed in the experiment), in fact [S] declined with time

$V_{\mathrm{t}_{\max }}$ do not rise above the start (real) value but fall with time. Again the presence of the counter nutrient tends to exacerbate the changes in parameter estimates.

Linearised plots of data from simulations in Figs. 2 \& 3 show changes in slopes with different incubation periods when internal feedback processes are most important in affecting transport rates; some examples are given in Fig. 4. Deviations from linear plots (Fig. 4) are indicative of significant substrate exhaustion at the lower values of [S]. Such information may be lost when using iterative curve fitting procedures alone. In situations where the experimenter is unaware of significant changes in [S], a linearised plot (e.g. [S] $V$ vs [S]) could be suggestive of the presence of 2 transport systems.

When estimates of $V^{l_{0}}$ are obtained for the simulations shown in Figs. 2 \& 3 using quadratic curve fits through the first 3 time points for cumulative transport (see 'Methods') and used to compute kinetic parameters (Table 2), close agreement with the correct, real values were obtained. This was so irrespective of whether the substrate concentration changed during the incubation, or even whether there was a counter nutrient present.

\section{Estimation of kinetic parameters from substrate removal from a single start [S]}

On some occasions, when modelling culture growth for example (e.g. Davidson et al. 1993), kinetic parameters may be estimated directly from substrate use during culture growth rather than using either estimates derived from chemostat studies or transport studies. At extremes, these incubations can be of very long duration starting with a small biomass (typical batch culture) through to high biomass systems which use the nutrient pulse so rapidly that internal feedback regulation may never become significant. Thesc extremes may be expected to yield kinetic parameters which are closer to $V_{\mathrm{a}_{\text {max }}} K_{\mathrm{a}}$ (kinetics for assimilation), or $V_{\mathrm{t}_{\max }}, K_{1}$ (kinetics for transport), respectively.

ANIM was configured to simulate a batch-culture, in continuous light, with 3 different start values for $\mathrm{N}$ sta-

Table 2. Values of $V_{t_{\max }}$ and $K_{1}$ derived from fits of rectangular hyperbolae through real values of $V^{\text {tu }}$ ('Real') or through estimates of $V^{t}$ obtained by fitting quadratic curves through the first 3 time points for transport from simulated experiments either in the absence ('Exp.') or presence ('Exp. $+\mathrm{N}$ source') of the indicated counter nutrient. See also 'Methods' $V_{t_{\max }}$ as $\mu g \mathrm{~N} \mathrm{mg}^{-1} \mathrm{Ch}^{-1}, K_{1}$ as $\mu \mathrm{M}$. Data are given $\pm 95 \%$ confidence limits for simulations starting at $2 \mathrm{~N}$ status (values of $Q$, the $N$ :C mass ratio). Substrate values [S] were either kept fixed during the incubation or declined (see also Figs. 2 \& 3)

\begin{tabular}{|c|c|c|c|c|c|c|}
\hline \multirow[t]{2}{*}{$Q$} & \multirow{2}{*}{$\begin{array}{c}\text { Test } \\
\text { substrate }\end{array}$} & \multirow{2}{*}{$\begin{array}{c}\text { Source of } \\
\text { data }\end{array}$} & \multicolumn{2}{|c|}{ Fixed [S] } & \multicolumn{2}{|c|}{ Declining [S] } \\
\hline & & & $V_{i_{\max }}$ & $K_{\mathrm{t}}$ & $V_{t_{\max }}$ & $K_{i}$ \\
\hline \multirow[t]{6}{*}{0.076} & $\mathrm{NO}_{3}^{-}$ & Real & $12.22 \pm 0.06$ & $0.98 \pm 0.01$ & $12.22 \pm 0.06$ & $0.98 \pm 0.01$ \\
\hline & & Exp. & $12.37 \pm 0.07$ & $1.00 \pm 0.02$ & $12.37 \pm 0.07$ & $1.00 \pm 0.02$ \\
\hline & & Exp. $+0.5 \mu \mathrm{M} \mathrm{NH}_{4}{ }^{+}$ & $13.15 \pm 0.06$ & $1.00 \pm 0.02$ & $13.00 \pm 0.08$ & $1.04 \pm 0.02$ \\
\hline & $\mathrm{NH}_{4}{ }^{+}$ & Real & $28.33 \pm 0.04$ & $0.99 \pm 0.00$ & $28.33 \pm 0.04$ & $0.99 \pm 0.00$ \\
\hline & & Exp. & $27.52 \pm 1.23$ & $0.91 \pm 0.13$ & $27.55 \pm 1.10$ & $0.94 \pm 0.12$ \\
\hline & & $\mathrm{Exp}+4 \mu \mathrm{M} \mathrm{NO}_{3}^{-}$ & $27.78 \pm 1.41$ & $0.90 \pm 0.15$ & $27.83 \pm 1.43$ & $0.94 \pm 0.16$ \\
\hline \multirow[t]{6}{*}{0.142} & $\mathrm{NO}_{3}^{-}$ & Real & $13.06 \pm 0.05$ & $1.01 \pm 0.01$ & $13.06 \pm 0.05$ & $1.01 \pm 0.01$ \\
\hline & & Exp. & $13.07 \pm 0.09$ & $1.00 \pm 0.02$ & $13.07 \pm 0.09$ & $1.00 \pm 0.02$ \\
\hline & & Exp. $+0.5 \mu \mathrm{M} \mathrm{NH}_{4}^{+}$ & $13.54 \pm 0.10$ & $1.03 \pm 0.02$ & $13.30 \pm 0.04$ & $1.02 \pm 0.01$ \\
\hline & $\mathrm{NH}_{4}{ }^{+}$ & Real & $16.97 \pm 0.05$ & $1.00 \pm 0.01$ & $16.97 \pm 0.05$ & $1.00 \pm 0.01$ \\
\hline & & Exp. & $16.97 \pm 0.11$ & $1.02 \pm 0.02$ & $16.97 \pm 0.11$ & $1.02+0.02$ \\
\hline & & Exp. $+4 \mu \mathrm{MNO}_{3}^{-}$ & $18.12 \pm 0.28$ & $1.12 \pm 0.05$ & $18.16 \pm 0.32$ & $1.14 \pm 0.06$ \\
\hline
\end{tabular}



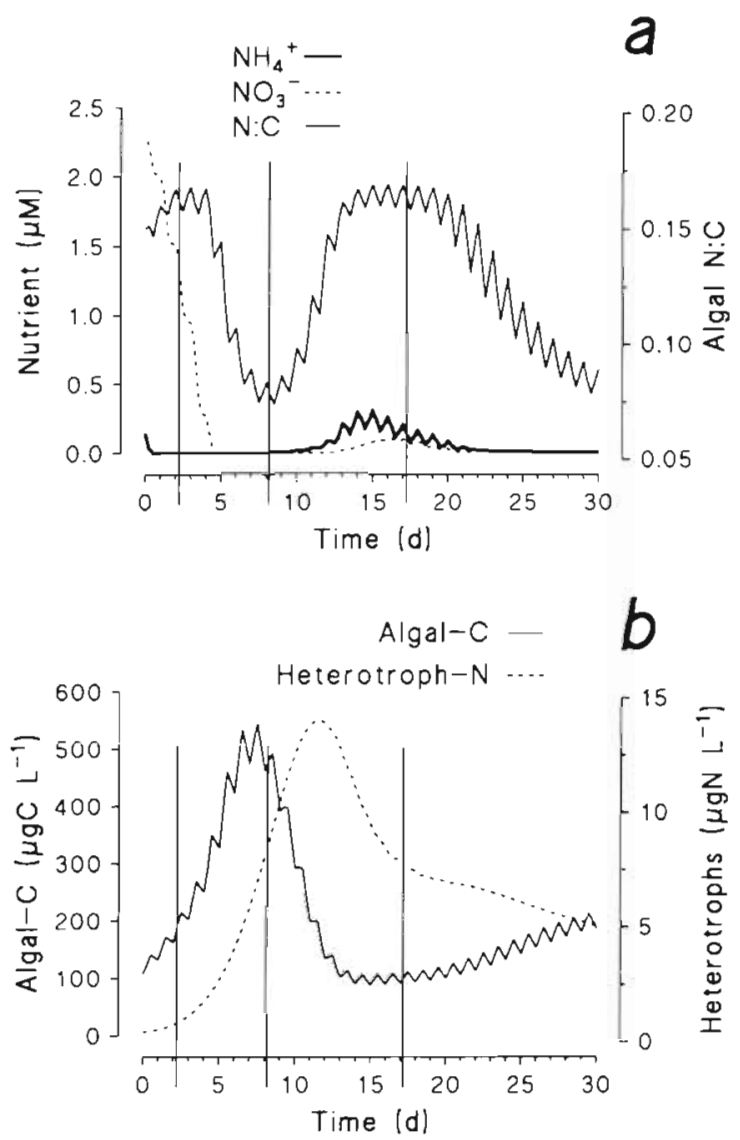

Fig. 7 Model output for a simulated natural event, showing changes (a) in nutrient concentrations and algal N:C status, and (b) in biomass of the algae and heterotrophs. The system was sampled for simulated ${ }^{15} \mathrm{~N}$ incubations around midday on

Days 2,8 and 17 as indicated by the vertical lines

ammonium or nitrate were run for $3 \mathrm{~h}$ centred around midday. The incubations were run in the presence of the residual concentration of the counter nutrient present at that time, but the concentration of the nutrient under test was varied as required (sometimes going below that actually present in the initial 'sample'). The atom $\%$ for ${ }^{15} \mathrm{~N}$ in test incubations was always set at 25 at. \%, natural abundance at 0.366 at. \%, and no isotope discrimination was assumed. Model output gave real transport rates into the algae, but rates were also computed using the ${ }^{15} \mathrm{~N}$ content to give transport into the total particulate (i.e. auto- + heterotrophic) fraction, in the algal fraction (i.e. $100 \%$ efficient post-incubation fractionation), and also in an incubation with no heterotrophs present (i.e. $100 \%$ efficient pre-incubation fractionation). Calculations of transport using ${ }^{15} \mathrm{~N}$ data followed the methods recommended by Collos (1987).

Results from the ${ }^{15} \mathrm{~N}$ incubations are given in Fig. 8 The Day 2 samples ( $\mathrm{N}$-replete cells growing mainly on nitrate) all gave good estimates of nitrate transport kinetics, except that in reality the amount of nitrate present $(\sim 1.4 \mu \mathrm{M})$ would have prevented the estimation of nitrate $K_{1}$. Estimates of ammonium $K_{\mathrm{t}}$ and $V_{\mathrm{t}_{\text {mat }}}$ taken over the first hour declined rapidly due to feedback processes; the substrate concentrations did not decrease markedly (not shown).

The samples from Day 8 ( $\mathrm{N}$-stressed cells now using mainly ammonium) showed a rapid fall of the estimated ammonium $V_{t_{\max }}$ with prolonged incubation (Fig. 8). This was also true for estimates of $K_{\mathrm{t}}$ for the first hour due to feedback events, but after this period the biomass was sufficiently high to decrease [S] significantly at the lower concentrations resulting in an increase in estimates of $K_{1}$ (Fig. 8, cf. events shown in Figs. 2 \& 3). This apparent increase in $K_{1}$ was actually greater as estimated by the ${ }^{15} \mathrm{~N}$ method because of the consequences of isotope dilution due to the regeneration of ammonium by heterotrophic activities (Fig. 9). This dilution was most significant at the lower values of [S]. Coincidentally, in the Day 8 incubation with no heterotrophs, no regeneration of ammonium and hence no isotope dilution, levels of ammonium fell rapidly (proportionately more so at low [S]); hence the similarity between kinetic parameters in this incubation and where the concentration of ${ }^{15} \mathrm{~N}$ ammonium fell during $\mathrm{N}$ regeneration. In all other simulations containing heterotrophs, the ${ }^{15} \mathrm{~N}$ atom \% of the test substrate (and counter nutrient) remained essentially constant over the $3 \mathrm{~h}$ period, though significant changes developed over longer periods ( 4 to $6 \mathrm{~h}$, not shown). Estimates of nitrate $V_{1_{n x}}$ were initially stable for Day 8 , but those for $K_{1}$ increased as a consequence of the effects of ammonium transport, and then estimates of both nitrate $V_{t_{\max }}$ and $K_{\mathrm{t}}$ decreased after $1.5 \mathrm{~h}$ with the decline in nitrate concentrations.

Day 17 samples (during a phase when nutrient cycling from the heterotrophs was matching demand by the phytoplankton) showed a steady decline in estimates of ammonium $K_{\mathrm{t}}$ and $V_{\mathrm{t}_{\max }}$ with incubation period. While estimates of nitrate $K_{\mathrm{t}}$ remained essentially constant, those for nitrate $V_{t_{\max }}$ more than doubled, especially in the sample incubated with no heterotrophs (Fig. 8; Day 17) where the residual ammonium declined quickly. This apparent increase in $V_{\mathrm{t}_{\max }}$ reflected a derepression of nitrate/nitrite reductase in the cells, enabling a more rapid assimilation of nitrate

\section{Consequences of the use of inaccurate kinetic parameters in ecosystem models}

In order to observe the consequences of running the ecosystem simulation with incorrect kinetic parameters for nutrient transport, the same simulation system 

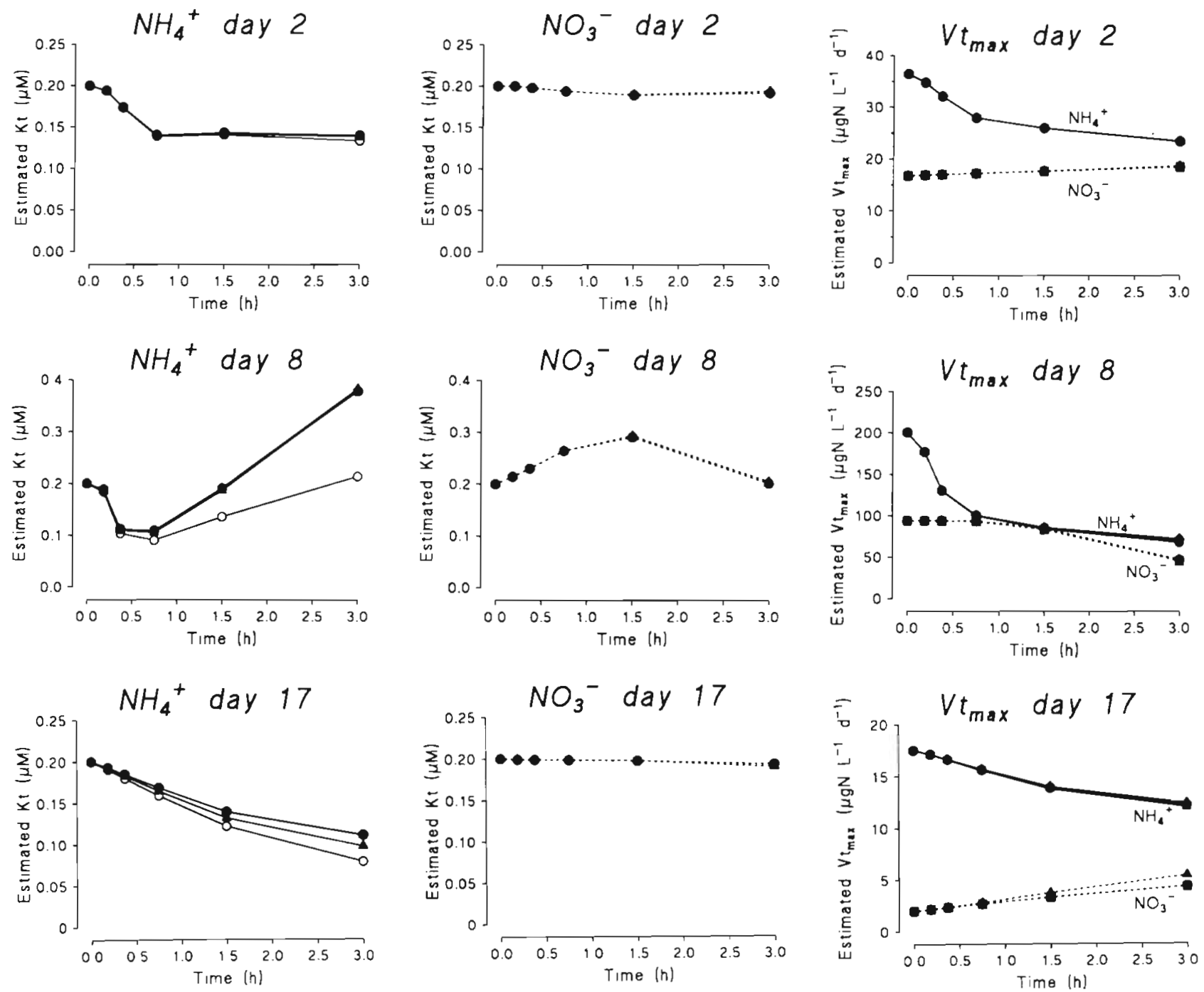

Fig. 8. Estimates of $K_{\mathrm{t}}$ (real value $0.2 \mu \mathrm{M}$ ) and $V_{\mathrm{tmax}}$ (real values at time 0 on the graphs) for samples taken from the system described in Fig. 7. Transport rates into algae in a mixed algae and heterotroph incubation are either real (open circles) or computed using the ${ }^{15} \mathrm{~N}$ results with sampling of either the whole particulate phase (closed circles) or just the algal component assuming $100 \%$ effective post-incubation fractionation (open triangles). In addition, an incubation with no heterotrophs (assuming a $100 \%$ effective pre-incubation fractionation: closed triangles) was run; in this instance, transport rates computed using ${ }^{15} \mathrm{~N}$ results

were identical to real transport rates (i.e. as for open circles). Data for nitrate: dashed lines; data for ammonium: solid lines

used for the ${ }^{15} \mathrm{~N}$ simulations was used but with values of $K_{\mathrm{t}}$ for ammonium and/or nitrate changed from the $0.2 \mu \mathrm{M}$ value used for both nutrients in the control simulation. $V_{t_{\max }}$ is not a constant (though it is effectively so for short incubations) but varies with the $N$ status ( $Q$ ) of the cell. Here the consequence was tested of using different-shaped response curves relating $V_{\mathrm{t}_{\max }}$ to $Q$ (giv-

Fig. 9. Changes in ammonium concentrations and in the ${ }^{15} \mathrm{~N}$ $\mathrm{NH}_{4}{ }^{+}$atom \% (at \%) during the incubations of the Day 8 sample in the presence of heterotrophs (see also Fig. 8, Day 8 closed circles). Only data for the 0.25 and $2.0 \mu \mathrm{M}$ incubations are given. The concentrations of nitrate were below $0.1 \mu \mathrm{M}$

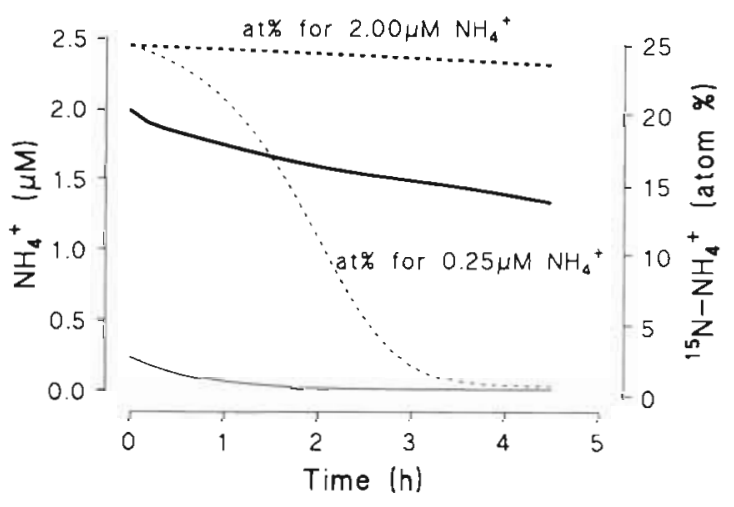


ing the model auxiliary $V_{\mathrm{tq}}$ ). Either this response curve was used as per Flynn et al. (1997) or both ammonium and nitrate curves were set the same as the control nitrate curve.

The behaviour of the algal model with these altered transport parameters (see inset in Fig. 10b), within an ecosystem model where the competitive nature of
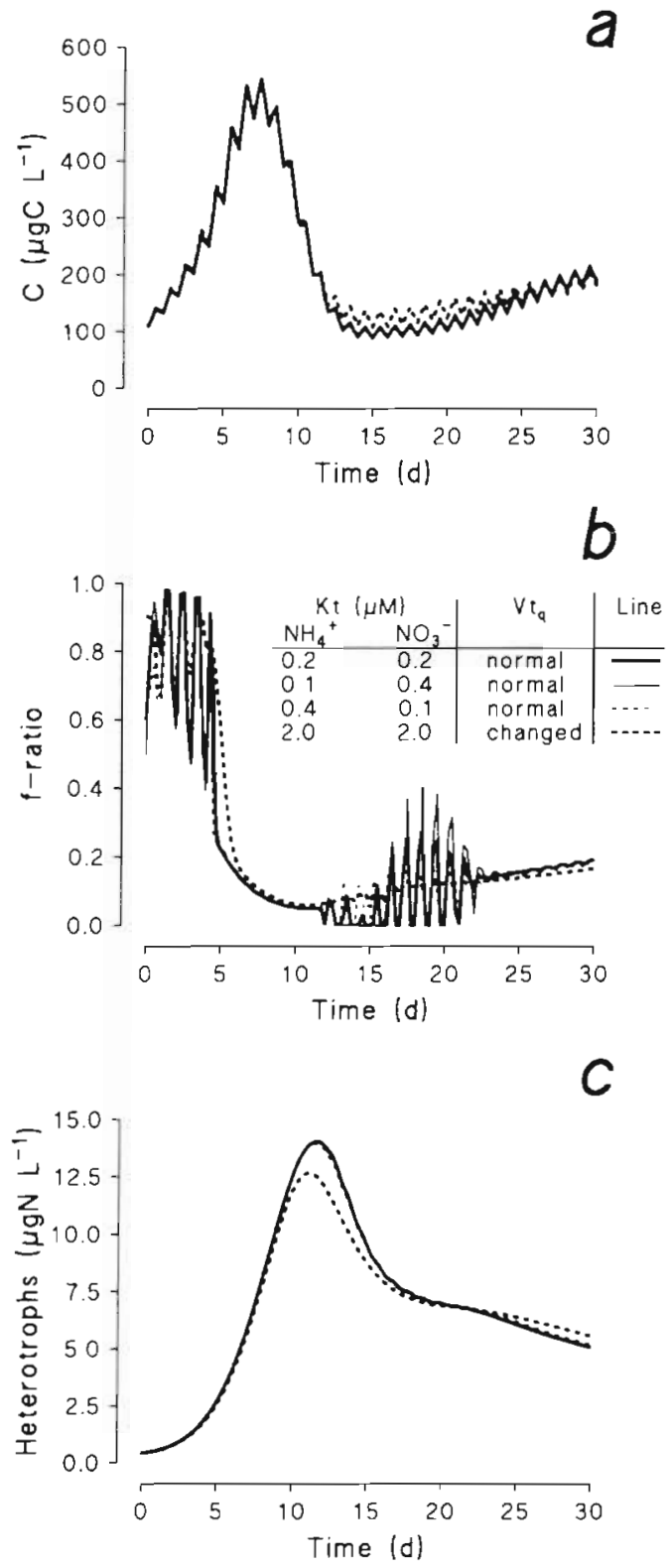

Fig. 10. Comparisons of model output for the ecosystem simulation shown in Fig. 7 when kinetic parameters for nutrient transport are altered. The plots show the results of changing the value of $K_{1}$ from the original value of $0.2 \mu \mathrm{M}$ for both $\mathrm{N}$ sources to values between $0.1 \mu \mathrm{M}$ and $2 \mu \mathrm{M}$, and of altering the shape of the response curve used by the model to difine $V_{t_{\text {max }}}$ for each nutrient as a function of the $N$ status of the algae (giving the parameter $V_{\mathrm{tq}}$ in the model) algal growth was tested against a background of predation, nutrient regeneration and changing substrate concentrations, is shown in Fig. 10. The value of the $\mathrm{f}$-ratio is given as

$$
\mathrm{f}=\frac{V_{\mathrm{t}_{\text {nitrate }}}}{V_{\mathrm{t}_{\text {nutrate }}}+V_{\mathrm{t}_{\text {dminumium }}}}
$$

The residual nutrient concentrations were similar to those shown for the control in Fig. 7, except in the $2 \mu \mathrm{M}$ $K_{\mathrm{t}}$ and 'changed' $V_{\mathrm{t} q}$ simulation, where the ammonium levels reached a maximum of $0.5 \mu \mathrm{M}$ around Day 15. Only in this latter simulation was a deviation of consequence noted in biomass values and in the f-ratio. This is partly due to an increased level of $N$ stress around Days 12 to 22 which enables the decoupling of nitrate use from photosynthesis and hence a loss in the diel oscillation of the f-ratio. As the grazing submodel operated in terms of $N$ (see Fasham et al. 1990), this resulted in lower levels of predation and hence lower heterotroph numbers. However, in general it appears that processes beyond transport into the algae were of overriding importance for the success of the algae in the simulation.

\section{DISCUSSION}

Eppley et al. (1969) remains the most widely used reference work for the affinity of marine phytoplankton transporters for $\mathrm{N}$ sources. This is so despite the development of alternative experimental techniques (e.g Raimbault 1984, Parslow et al. 1984, 1985), improvements in analytical techniques (Raimbault et al. 1990, Garside \& Glover 1991, McCarthy et al. 1992), and the appreciation that 'surge' transport will adversely affect measurements (reviewed in Morel 1987 and Harrison et al. 1989). In addition, various other potential complications have been identified, such as the effects of cell size, mucilage, swimming, and other factors rate limiting substrate diffusion (Aksnes \& Egge 1991).

The consequences of the sources of error listed in Table 1 , for the estimation of $K_{1}$ and $V_{t_{\max }}$, are summarized in Table 3 . Simulations indicated that, generally, feedback regulation of transport (which occurs most rapidly at higher [S]j results in a decrease in estimates of both $V_{t_{\max }}$ and $K_{1}$ (apparent increase in porter affinity). Estimates of $K_{t}$ fall because the feedback processes occur more rapidly at higher values of [S], skewing the hyperbolic curve to give a steeper initial rise. Decreases in [S] during the incubation (which affect rates at lower [S] disproportionately) result in an increase in the estimated value of $K_{1}$ as well as a decrease in estimated $V_{t_{\max }}$ (Table 3 ). Because of the higher rates of transport and assimilation for ammo- 
nium, this is likely to result in errors being most significant for ammonium. The methods of Eppley et al. (1969) and of many others (see Harrison et al. 1989) were reliant on the substrate depletion method. Intuitively one may not be comfortable with such an approach because it conflicts with the need for stable values of [S] while estimating transport. However, the simulations presented here (Fig. 3) suggest that except in very short incubations the errors may be no worse than measuring transport into the cells with no deviation in [S] (Fig. 2). This is because the Type I and II errors (Table 3 ) tend to cancel each other for $K_{1}$ while estimates of $V_{\pi_{\max }}$ are only affected if there is a significant decline in the highest values of [S].

Parameters for transport kinetics derived from the disappearance of substrate in batch culture systems (Fig. 5) appear to be best reserved for parameterising models of those culture systems, giving reasonable estimates of the steady-state assimilation constants $K_{a}$ and $V_{a_{\max }}$ without the complications of using chemo stats. However, the model predicts that kinetic parameters for transport could be estimated quickly and with reasonable accuracy with this single substrate addition approach when using high biomass incubations (Fig. 5). Adequate data sets may be obtained using an initial substrate concentration of less than $4 \mu \mathrm{M}$ (rather than the $10 \mu \mathrm{M}$ used in the simulation) hence enabling the use of a lower biomass.

Without techniques which give estimates of transport in the absence of feedback or significant substrate depletion, the use of quadratic equations to estimate $V^{t_{1}}$ from measurements of cumulative transport may give a good estimate of the real value of this parameter (Table 2). Where feedback is very rapid (within seconds, as may occur for nitrate entering cells with a small nitrate pool and repressed nitrate reductase) more frequent collection of data would be required. The biggest problems are to be encountered where there are very few (perhaps only a single) estimates of transport at each value of [S]. This is most likely with field experiments. Depending on the end point of the incubation and the stability of [S], estimated $K_{1}$ values could be anywhere from 50 to $200 \%$ of real values, and estimates of $V_{t_{\max }}$ down to $<50 \%$ of real values (Fig. 8). Greater deviations in accordance with Glibert \& Goldman (1981) can be simulated using starting conditions of greater $N$ stress or different equations relating $V_{1_{\text {mat }}}$ to $Q$. The situation is worsened in longer incubations than the $3 \mathrm{~h}$ period simulated here because of nutrient cycling (with attendant isotope dilution in ${ }^{15} \mathrm{~N}$ incubations) and the greater likelihood of intracellular feedback interactions. With a higher biomass the lower substrate concentrations may be depleted significantly ( $K_{\mathrm{t}}$ is then overestimated, a situation most likely for ammonium). In field conditions, consumption or regeneration (Kirchman 1994, Middelboe et al. 1995, Shiah \& Ducklow 1995) of ammonium by bacteria will exacerbate these problems. If bacteria are net consumers then studies of assimilation by them or by the total algal-bacterial population will be subject to the same types of problem indicated here. The situation over the course of an entire day (rather than just the light phase) needs to be considered using a model capable of reproducing diel events, though feedback processes in nutrient transport will be just as important.

All the above assumed that after entry into the cell the $\mathrm{N}$ remained there for the period of the incubation. This may not be so for phytoplankton (Collos et al. 1992, Bronk \& Glibert 1994, Bronk et al. 1994, Sciandra \& Amara 1994, Flynn \& Flynn 1998) any more than for bacteria (Middelboe et al. 1995). Assuming that any release of ${ }^{15} \mathrm{~N}$ is most likely to occur roughly in proportion to initial transport rates into the cell, one may expect a decrease in apparent $V_{t_{\max }}$ and $K_{\mathrm{t}}$ with such a loss.

If values of $V$ are determined at few or a single sample time point in an incubation with non-stable [S], for different populations of different nutrient histories, one

Table 3. Summary of the consequences of the errors listed in Table 1 Because these interact, the end result depends on the duration and magnitude of the causal factor(s). $V_{1_{\max }} / V_{i \max }$ and $K_{1} / K_{\mathrm{a}}$ are maximum transport/assimilation rates and the substrate concentration required to support half $V_{\mathrm{t}_{\max }} / \bar{V}_{\mathrm{a}_{\max }}$ respectively

\begin{tabular}{|c|c|c|c|c|}
\hline Type & Cause & Likely changes in estimated kinetic parameters & Associated error & Figs. \\
\hline I & Incubation period & $\begin{array}{l}K_{1} \text { declines to } K_{a}, V_{t_{\max }} \text { declines to } V_{\mathrm{a}_{\max }} \text { unless } \\
\text { derepression occurs }\end{array}$ & & $2,3,5,8$ \\
\hline II & {$[S]$ falls } & $\begin{array}{l}K_{\mathrm{t}} \text { rises, } V_{\mathrm{tmax}} \text { unchanged as long as maximum }[S] \\
\text { does not decline significantly }\end{array}$ & I & $3,5,8$ \\
\hline III & $\begin{array}{l}\text { Ammonium-nitrate } \\
\text { interaction }\end{array}$ & $K_{1}$ declines, $V_{t_{\max }}$ declines & I, II & $2,3,8$ \\
\hline IV & $\begin{array}{l}\text { Changes in isotopic } \\
\text { composition }\end{array}$ & $\begin{array}{l}\text { Depends on changes in total [S] for test and counter } \\
\text { nutrient and in }{ }^{15} \mathrm{~N}:{ }^{4} \mathrm{~N} \text { ratio }\end{array}$ & I, II, III & 8 \\
\hline
\end{tabular}


could erroneously obtain a series of $K_{\mathrm{t}}$ values giving the impression of changes in transport affinity as the cells became progressively more $\mathrm{N}$ starved. If [S] remained stable (or essentially so) during the incubation then increasing $N$ stress may give an apparent decrease in $K_{t}$ (i.e. higher affinity). Similar problems may occur when temperature is a variable rather than $\mathrm{N}$ status because of the consequences of the rates of transport and incorporation on feedback. Incubations at higher temperature and constant [S] may misleadingly give the impression of enhanced transport affinity (decreased $K_{\mathrm{t}}$ ). However, if [S] declined during the incubation then estimates of $K_{\mathrm{t}}$ would increase at high temperature, as the fall in [S] would be most significant at low concentrations. As $Q_{10}$ for nutrient transport may be considerably higher than for growth, quite modest changes in temperature may have significant effects (Li 1980, Priscu et al. 1989).

Simulations of the use of low temperature to help in the determination of kinetic parameters (Fig. 6) by partly decoupling transport from feedback controls, as proposed by Raimbault (1984), suggest that this method would only work for species with a large internal nitrate pool. This is because transport is now adversely affected by the internal accumulation of nitrate which is not removed so rapidly for conversion to ammonium. [Raimbault (1984) used diatoms which have relatively large nitrate pools.] An alternative is to use analogues of the substrates themselves so, while transinhibition will still occur as the inorganic nutrient pool fills, feedback from organic products will be relieved (Balch 1985). However, analogues may not be transported with the same kinetics as real substrates, while inhibitors of biochemical processes may have various other side effects.

Other changes may be expected depending on whether assimilatory pathways are fully functional and depending on the maximum size of the inorganic $N$ pool. For example if nitrate/nitrite reductase is not fully derepressed, there may be a short-term initial transport of nitrate at a high rate, a pause once the internal pool was full, and then a continuation once significant reduction started (causing the increase in estimated $V_{t_{m+x}}$ for nitrate in Day 17; Fig. 8). This and other problems may be significant (Gotham \& Rhee 1981, Collos 1983, Harrison et al. 1989, Dortch et al. 1991a, Garside 1991), but as the longer incubations are perturbing the cell physiology (resulting in 'shift-up'; Garside 1991), changes in the values of transport kinetics are only to be expected. The different phases of nutrient transport identified by Collos (1983), with surge, internal and external control, are a continuum. Transport is rarely wholly limited by either internal or external factors but represents a balance between them controlled by cell physiology. Unfortunately any manipulation of the samples can disturb the $\mathrm{C}-\mathrm{N}$ physiology of cells rapidly (Flynn et al. 1994). Methods such as the use of flow cytometry (Lipschultz 1995) will inevitably affect the kinetics of nutrient transport because of the periods of manipulation before or after incubation and/or the effects of light.

The estimation of kinetic parameters is also complicated by the presence of residual nutrient concentrations. Apart from the inability to then determine transport at nutrient concentrations lower than the residual level in the medium (giving the mathematical problems shown in Case 2 of Berges et al. 1994), in situations where the counter nutrient is present, the result depends on the nutrient history of the cells and the relative concentrations of the nutrients (see Dortch et al. $1991 \mathrm{~b}$ ), and also whether those concentrations change significantly over the period of the incubation (Fig. 8). There are important implications, beyond kinetic studies, for estimates of uptakc in field research where ${ }^{15} \mathrm{~N}$ substrates are added in more than trace quantities (not uncommon at low in situ ammonium concentrations). These problems extend to interactions with organic $N$ sources in algae and in other microbes (Lund 1987. Middelboe et al. 1995, Preston et al. 1996).

The estimation of kinetic parameters for transport, and indeed of transport rates in general, is clearly problematic. Within the model, as in reality, these are post-transport processes associated with nutrient incorporation which are an important part of that problem, as indicated by the dynamics of 'surge uptake' and nutrient interactions. For competition it is not good enough to have the most efficient transport systems if the following biochemical processes cannot keep pace with the rate of nutrient entering the cell Perhaps we should not assign too much importance to differences in kinetic parameters for transport because, firstly, they are likely to be subject to various errors because of methodological problems, and those problems will vary for different organisms with different growth rates and of different $\mathrm{N}$ status, and secondly, provided that

$$
V_{I_{\max }} \frac{[\mathrm{S}]}{[\mathrm{S}]+K_{\mathrm{t}}} \geq V_{\mathrm{a}_{\max }}
$$

transport is not the limiting factor and rates will be modulated by internal feedback mechanisms to optimise transport relative to biochemical requirements. Estimates of kinetic parameters are made using cells which are subject to restrictions arising from diffusion across hydrodynamically induced boundary layers associated with cell size, shape, and mucilage, or with the ion handling time (Aksnes \& Egge 1991). However, provided there is sufficient leeway in the system so the above equation is satisfied then the internal biochemistry again becomes the overriding factor 
One could argue for simulations of ecologically significant events that $K_{\mathrm{a}}$ and $V_{\mathrm{a}_{\max }}$ would be of more importance than $K_{\mathrm{t}}$ and $V_{\mathrm{lmax}^{\prime}}$ after all, are not phytoplankton (and other microbes) in nature living under a quasi steady state? The answer must be no, the assimilation constants are not sufficient because these steady-state parameters give no indication of the ability to compete for a pulse of nutrient under transient conditions. The importance of both $V_{\mathrm{l}_{\text {mux }}}$ and $K_{\mathrm{t}}$ is portrayed by the value of the affinity of the organism for the substrate (i.e. $V_{1_{\max }} K_{t}^{-1}$ ). Harrison et al. (1989), in a critical review of pre-1989 works on uptake kinetics in phytoplankton, argue that this affinity, $\alpha$, is a much better indicator of competitive advantage than the transport affinity, $K_{\mathrm{t}}$. Unfortunately, as $\alpha$ takes the value of the ratio of 2 components, both of which are prone to errors in estimation, $\alpha$ is not robust. Other factors than $\alpha$ may be equally or more important for competition under transient conditions, such as an ability to accumulate large internal pools of the inorganic nutrient (Grover 1991, Stolte \& Riegman 1996) or decouple $\mathrm{N}$ assimilation and $\mathrm{C}$ fixation over the short term. Transport itself ceases to be the (sole) limiting factor and it is necessary to have more detailed information for intracellular processes (Haney \& Jackson 1996).

While much effort has been placed on determining transport kinetic parameters, applications of these data have been limited (e.g. Riegman et al. 1990). However, such information is required in models, especially if one wishes to include a submodel of microbial physiology such as ANIM. Given the difficulties in determining kinetic parameters for transport it then becomes important to question the consequences of using erroneous parameters in simulations. In the ecosystem simulation, even doubling $K_{t}$ for one nutrient and halving it for the other had very little effect (compare Figs. 10 \& 7). $K_{\mathrm{t}}$ had to be increased by an order of magnitude (in this case moved to $2 \mu \mathrm{M}$ for both nutrients) and the values of $V_{L_{\max }}$ for ammonium made less advantageous, before a more significant deviation was seen. The effect of altering the relationship between $Q$ and $V_{t_{\text {mix }}}$ in ANIM has been considered by Flynn \& Fasham (1997); the value is not critical for performance of the model though it is preferable to at least know the form of the relationship.

If all else is equal, a cell with lower $K_{\mathrm{l}}$ and/or higher $V_{t_{\max }}$ will be at a competitive advantage at low [S]. However, it is likely that the very biochemical (posttransport) processes which help to confound estimations of $K_{\mathrm{l}}$ and $V_{\mathrm{t}_{\max }}$ are equally important in defining the competitive advantages of individual species. Factors affecting other aspects of physiology, including interactions between other nutrients (e.g. N-P and $\mathrm{N}$-Si), together with details for the operation of other biological components, are also all important.
Acknowledgements. This work was supported by the NERC (UK). The author thanks Mike Fasham for help during the development of the ecosystem simulation, and Keith Davidson and anonymous referees for comments on earlier versions of the manuscript.

\section{LITERATURE CITED}

Aksnes DL, Egge JK (1991) A theoretical-model for nutrientuptake in phytoplankton. Mar Ecol Prog Ser 70:65-72

Balch WM (1985) Lack of an effect of light on methylamine uptake by phytoplankton. Limnol Oceanogr 30:665-674

Berges JA, Montagnes DJS, Hurd CL, Harrison PJ (1994) Fitting ecological and physiological data to rectangular hyperbolae: a comparison of methods using Monte Carlo simulations. Mar Ecol Prog Ser 114:175-183

Bronk DA, Glibert PM (1994) The fate of the missing ${ }^{15} \mathrm{~N}$ differs among marine systems. Limnol Oceanogr 39:189-195

Bronk DA, Glibert PM, Ward BB (1994) Nitrogen uptake, dissolved organic nitrogen release, and new production. Science 265:1843-1846

Caperon J (1968) Population growth in micro-organisms limited by food supply. Ecology 49:715-721

Cochlan WP, Harrison PJ, Denman KL (1991) Diel periodicity of nitrogen uptake by marine-phytoplankton in nitraterich environments. Limnol Oceanogr 36:1689-1700

Collos Y (1980) Transient situations in nitrate assimilation by marine diatoms. I. Changes in uptake parameters during nitrogen starvation. Limnol Oceanogr 25:1075-1081

Collos Y (1983) Transient situations in nitrate assimilation by marine diatoms. 4. Non-linear phenomena and the estimation of the maximum uptake rate. J Plankton Res 5 $677-691$

Collos $Y$ (1987) Calculations of ${ }^{15} \mathrm{~N}$ uptake rates by phytoplankton assimilating one or several nitrogen sources. Appl Radiat Isot 38:275-282

Collos Y, Dohler G, Biermann I (1992) Production of dissolved organic nitrogen during uptake of nitrate by Synedra planctonica. J Plankton Res 14:1025-1029

Davidson K, Cunningham A, Flynn KJ (1993) Modelling temporal decoupling between biomass and numbers during the transient nitrogen-limited growth of a marine phytoflagellate. J Plankton Res 15:351-359

Dortch Q (1990) The interaction between nitrate and ammonium uptake in phytoplankton Mar Ecol Prog Ser 61: 183-201

Dortch Q, Clayton JR, Thoresen SS, Bressler SL, Ahmed Sl (1982) Response of marine phytoplankton to nitrogen deficiency: decreased nitrate uptake vs enhanced ammonium uptake. Mar Biol 70:13-19

Dortch Q. Thompson PA, Harrison PJ (1991a) Variability in nitrate kinetics in Thalassiosira pseudonana (Bacillariophyceae). J Phycol 27:35-39

Dortch Q. Thompson PA, Harrison PJ (1991b) Short-term interaction between nitrate and ammonium uptake in Thalassiosira pseudonana: effect of preconditioning nitrogen source and growth rate. Mar Biol 110:183-193

Droop MR (1968) Vitamin $B_{12}$ and marine ecology IV. The kinetics of uptake growth and inhibition in Monochrysis lutheri. J Mar Biol Assoc UK 48:689-733

Dugdale RC, Goering JJ (1967) Uptake of new and regenerated forms of nitrogen in primary production. Limnol Oceanogr 12:196-206

Eppley RW, Rogers JN, McCarthy JJ (1969) Half-saturation constants for uptake of nitrate and ammonium by marine phytoplankton. Limnol Oceanogr 14:912-919 
Fasham MJR, Ducklow HW, McKelvie SM (1990) A nitrogenbased model of plankton dynamics in the oceanic mixed layer. J Mar Res 48:591-639

Flynn KJ (1991) Algal carbon-nitrogen metabolism: a biochemical basis for modelling the interactions between nitrate and ammonium uptake. J Plankton Res 13:373-387

Flynn KJ, Fasham MJR (1997) A short version of the ammonium-nitrate interaction model. J Plankton Res 19 $1881-1897$

Flynn KJ, Fasham MJR, Hipkin CR (1997) Modelling the interactions between ammonium and nitrate uptake in marine phytoplankton. Phil Trans R Soc Lond B 352 $1625-1645$

Flynn KJ, Flynn K (1998) The release of nitrite by marine dinoflagellates - development of a mathematical simulation. Mar Biol 130:455-470

Flynn KJ, Jones KJ, Raine R, Richards J, Flynn K (1994) Use of intracellular amino acids as an indicator of the physiological status of natural dinoflagellate populations. Mar Ecol Prog Ser 103:175-186

Garside C (1991) Shift-up and the nitrate kinetics of phytoplankton in upwelling systems. Iimnol Oceanogr 36 $1239-1244$

Garside C, Glover HE (1991) Chemiluminescent measurements of nitrate kinetics. 1 Thalassiosira pseudonana (clone-3h) and neritic assemblages. J Plankton Res 13:5-19

Glibert PM, Garside C (1992) Diel variability in nitrogenous nutrient-uptake by phytoplankton in the Chesapeake Bay plume. J Plankton Res 14:271-288

Glibert PM, Goldman JC (1981) Rapid ammonium uptake by marine phytoplankton. Mar Biol Lett 2:25-31

Goldman JC, Glibert PM (1982) Comparative rapid ammonium uptake by four species of marine phytoplankton. Limnol Oceanogr 27:814-827

Gotham IJ, Rhee GY (1981) Comparative kinetic studies of nitrate-limited growth and nitrate uptake in phytoplankton in continuous culture. J Phycol 17:309-314

Grover JP (1991) Resource competition in a variable environment - phytoplankton growing according to the variableinternal-stores model. Am Nat 138:811.-835

Guillard RRL (1975) Culture of phytoplankton for feeding marine invertebrates. In: Smith WL, Chanley MH (eds) Culture of marine invertebrate animals. Plenum Press, New York, p 29-60

Haney JD, Jackson GA (1996) Modeling phytoplankton growth rates. J Plankton Res 18:63-85

Harrison PJ, Parslow JS, Conway HL (1989) Determination of nutrient uptake kinetic parameters: a comparison of methods. Mar Ecol Prog Ser 52:301-312

Harrison WG, Harris LR, Irwin BD (1996) The kinetics of nitrogen utilization in the oceanic mixed layer: nitrate and ammonium interactions at nanomolar concentrations. Limnol Oceanogr 41:16-32

Kirchman DL (1994) The uptake of inorganic nutrients by heterotrophic bacteria. Microb Ecol 28:255-271

Li WKW (1980) Temperature adaptation in phytoplankton: cellular and photosynthetic characternstics In: Falkowski PG (ed) Primary productivity in the sea. Plenum Press. New York, p 259-279

Lipschultz F (1995) Nitrogen-specific uptake rates of marinephytoplankton isolated from natural-populations of particles by flow-cytometry. Mar Ecol Prog Ser 123:245-258

Lund BA (1987) Mutual interference of ammonium, nitrate and urea on uptake of ${ }^{15} \mathrm{~N}$ sources by the marine diatom Skeletonema costatum. J Exp Mar Biol Ecol 113:167-180 McCarthy Jj (1981) The kinetics of nutrient utilization. Can

Editorial responsibility: Otto Kinne (Editor),

OIdendorf/Luhe, Germany
Bull Fish Aquat Sci 210:211-233

McCarthy JJ, Garside C, Nevins JL (1992) Nitrate supply and phytoplankton uptake kinetics in the euphotic layer of a Gulf Stream warm-core ring. Deep Sea Res A 39:393-403

Middelboe M, Borch NH, Kirchman DL (1995) Bacterial utilization of dissolved free amino acids, dissolved combined amino acids and ammonum in the Delaware Bay estuary: effects of carbon and nitrogen limitation. Mar Ecol Prog Ser 128:109-120

Morel FMM (1987) Kinetics of nutrient-uptake and growth in phytoplankton. J Phycol 23:137-150

Parslow JS, Harrison PJ, Thompson PA (1984) Use of a selfcleaning in-line filter to continuously monitor phytoplankton nutrient uptake rates. Can J Fish Aquat Sci 41 $540-544$

Parslow JS, Harrison PJ, Thompson PA (1985) Ammonium uptake by phytoplankton on a filter: a new high-resolution technique. Mar Ecol Prog Ser 25:121-129

Preston T, Bury S, Mcmeekin B, Slater C (1996) Isotope-dilution analysis of combined nitrogen in natural waters. 2. Amino acids. Rapid Commun Mass Spectrom 10:965-968

Priscu JC, Palmisano AC, Priscu LR, Sullivan CW (1989) Temperature dependence of inorganic nitrogen uptake and assimilation in Antarctic sea-ice microalgae. Polar Biol 9: $443-446$

Raimbault P (1984) Influence of temperature on the transient response in nitrate uptake and reduction by four marine diatoms. J Exp Mar Biol Ecol 84:37-53

Raimbault P, Gentilhomme V (1990) Short- and long-term responses of the marine diatom Phaeodactylum tricornutum to spike additions of nitrate at nanomolar levels. J Exp Mar Biol Ecol 135:161-176

Raimbault P. Slawyk G, Gentilhomme V (1990) Direct measurements of nanomolar nitrate uptake by the marine diatom Phaeodactylum tricornutum (Bohlin)-implications for studies of oligotrophic ecosystems. Hydrobiologia 207:311-318

Raven JA (1980) Nutrient transport in microalgae. Adv Microb Physiol 21:47-226

Riegman R, Colijn F, Malschaert JFP, Kloosterhuis HT, Cadee GC (1990) Assessment of growth-rate limiting nutrients in the North Sea by the use of nutrient-uptake kinetics. Neth $J$ Sea Res 26:53-60

Sciandra A, Amara R (1994) Effects of nitrogen limitation on growth and nitrite excretion rates of the dinoflagellate Prorocentrum minimum. Mar Ecol Prog Ser 105:301-309

Shiah FK, Ducklow HW (1995) Regulation of bacterial abundance and production by substrate supply and bacterivory: a mesocosm study. Microb Ecol 30:239-255

Stolte W, Riegman R (1996) A model approach for size selective competition of marne phytoplankton for fluctuating nitrate and ammonium. J Phycol 32:732-740

Syrett PJ (1981) Nitrogen metabolısm ot microalgae. Can Bull Fish Aquat Sci 210:182-210

Syrett PJ, Flynn. KJ, Molloy CJ, Dixon GK, Peplinska AM, Cresswell RC (1986) Effects of nitrogen deprivation on rates of uptake of nitrogenous compounds by the marine diatom Phaeodactylum tricornutum Bohlin. New Phytol 102:39-44

Wheeler PA (1983) Phytoplankton nitrogen metabolism. In: Carpenter EJ, Capone DG (eds) Nitrogen in the marine environment. Academic Press, New York, p 309-346

Zehr JP, Falkowski PG, Fowler J, Capone DG (1988) Coupling between ammonium uptake and incorporation in a marine diatom-experiments with the short-lived radioisotope ${ }^{13}$ N. Limnol Oceanogr 33:518-527

Submitted: November 28, 1997; Accepted: May 16, 1998 Proofs received from author(s): July 13, 1998 